\title{
Nuevas recomendaciones frente a las actuales controversias en infección urinaria. Resumen ejecutivo
}

\author{
New recommendations against the current controversies in \\ urinary tract infection. Executive summary
}

Comité de Nefrología (2011-2013)

Secretaria: Dra. Marta Adragna

Prosecretaria: Dra. Andrea Exeni

Vocales: Dra. Laura Alconcher, Dr. Juan I. Ayub, Dr. Carlos Cobeñas, Dra. Paula Coccia, Dra. Adriana Santiago, Dra. Rosana Salim

Con la colaboración de: Comité de Diagnóstico por Imágenes, Comité de Infectología, Comité de Urología Pediátrica (Sociedad Argentina de Urología).

Véase el texto completo en formato electrónico, en la sección "Consensos" del sitio web de la Sociedad Argentina de Pediatría.

http:/ /dx.doi.org/10.5546/aap.2015.579

\section{INTRODUCCION}

Frente a la diversidad de opiniones y controversias surgidas de guías extranjeras (NICE, Reino Unido, 2007 y AAP, EE. UU., 2011), las recomendaciones del Comité de Nefrología en 2008 (Nefrología Pediátrica $2^{\text {da }}$ edición) y toda la nueva evidencia disponible, se consensuaron las siguientes recomendaciones con el objetivo general de mejorar la detección y el pronóstico de la patología estructural y funcional de la vía urinaria que condiciona daño renal definitivo, a través de su manifestación más frecuente: la infección urinaria (IU).

Para ello se revisaron los conceptos de diagnóstico y tratamiento a la luz de las publicaciones extranjeras y la experiencia de expertos locales a fin de exponer los nuevos lineamientos adecuados a la situación actual en nuestro país.

El texto redactado hace foco sobre Dra. Marta Adragna: marta.adragna@ gmail.com

Finanaciamiento: Ninguno

Recibido: 23-7-2015 Aceptado: 23-7-2015
Incluye además un anexo con definiciones, presentación clínica por edades y factores de riesgo, diagnóstico de laboratorio y toma de muestra y un enfoque particular de la infección urinaria baja.

\section{Evaluación diagnóstica por imágenes}

Los principales objetivos de los estudios con imágenes en la IU son:

- Detectar los pacientes que presenten anomalías estructurales del tracto urinario y/o reflujo vésicoureteral (RVU), hasta ese momento silentes. La identificación de estas anomalías permite tomar medidas preventivas que eviten nuevas infecciones urinarias y de esta manera reducir el riesgo de desarrollar daño renal adquirido por escaras pielonefríticas o agravar un daño preexistente.

- Detectar el daño renal congénito o adquirido. El congénito es debido a displasia y/o hipoplasia renal que frecuentemente está asociado a anomalías graves de la vía urinaria. Este grupo de pacientes son en su mayoría varones con RVU masivo 
bilateral y es el grupo con mayor riesgo de desarrollar enfermedad renal crónica (ERC).

El daño renal congénito y/o adquirido puede tener consecuencias tales como hipertensión arterial (HTA), enfermedad renal crónica y complicaciones del embarazo.

La ecografía renal y vesical, la cistouretrografia miccional (CUGM) y el centellograma renal con Tc $99^{\mathrm{m}}$ marcado con ácido dimercaptosuccínico (DMSA Tc $99^{\mathrm{m}}$ ) constituyen los métodos de imágenes centrales en la evaluación de un niño con IU.

a. El uso sistemático de la ecografía en el control del embarazo puso en evidencia que el RVU asociado a daño renal y ERC es el que se presenta principalmente en varones con las características comentadas. Lamentablemente, a pesar de ser el primer eslabón en la cadena de detección de patología renal prenatal, no en todos los embarazos se realizan las 3 ecografías de control y, aun realizándose, a veces no se observan correctamente los riñones, o no se miden o su informe nada dice de ellos.

b. La probabilidad de desarrollar daño renal en los pacientes con RVU varía con el grado del mismo; reflujos de bajo grado raramente producen daño siendo esto mucho más frecuente en los de mayor grado.

c. El daño no depende del RVU en sí sino de la IU a la que favorecen.

d. La CUGM y los estudios de medicina nuclear utilizan una considerable dosis de radiación (la CUGM equivale a 25 a 160 radiografías de tórax y la DMSA renal a 50).

Todo esto produjo controversias sobre cuál sería la estrategia diagnóstica de imágenes más efectiva en niños con IU y llevaron a cambios en los algoritmos de estudio. Por ello a todo paciente con primer episodio de infección urinaria (IU) se le debe realizar ecografía renal y vesical (pre y post miccional, en el caso que controle esfinteres), independientemente del sexo, edad y tipo de IU (alta o baja), aun aquellos con ecografía prenatal normal: la ecografía es un método no invasivo, que no conlleva dosis de radiación, y que realizada por un operador entrenado, preferentemente pediátrico o con experiencia en niños, brinda información muy valiosa. Por lo tanto, es fundamental para el pediatra contar con una ecografía renal confiable.

El documento describe las características de ésta en cada uno de los puntos que deben poder evaluarse en una ecografía tales como: posición, forma, tamaño (cómo deben estar medidos, su importancia en el diagnóstico de enfermedad aguda o crónica), ecoestructura del parénquima, relación y diferenciación córticomedular, espesor parenquimatoso, presencia de ectasia o dilataciones en pelvis, cálices y cómo deben estar medidas, ya que en condiciones normales el sistema excretor no debería verse, y las características de la vejiga. Es sabido no obstante que la sensibilidad y especificidad de la ecografía para detectar el RVU y daño es baja y solo permite inferir su presencia indirectamente.

En cuanto a otros estudios, se explica los fundamentos por los que se realizará CUGM a los menores de un año y en caso de que presenten RVU se pedirá centellograma DMSA. A los que tengan un año o más, no se le realizarían más estudios. En caso de recurrencia, se valorará también por edad ya que las infecciones urinarias recurrentes (IUR), presenten o no RVU, tienen riesgo de desarrollar daño renal, por lo que el centellograma se les debe realizar a todos. El RVU lo buscaremos en el menor de 1 año sistemáticamente y en el mayor de 1 año que muestre centellograma patológico con CUGM.

Los niños con ecografía renal patológica deberán ser referidos al especialista para que evalúe la secuencia de estudios acorde a la patología hallada.

\section{Quimioprofilaxis en la infección urinaria}

La quimioprofilaxis es otro de los aspectos más controvertidos en el contexto de niños que han presentado episodios de IU. Existen estudios publicados que muestran evidencias a favor y en contra de la misma. La mayoría presentan sesgos de número de pacientes incluidos, diferentes uropatías, edades, tiempo de seguimiento etc. No obstante se ha convenido en indica quimioprofilaxis a: los menores de un año con primer episodio de IU que aún no se hayan realizado estudios de imágenes y los que tengan RVU de cualquier grado, los mayores que tengan RVU mayor o igual a grado III, los que presentan escaras y RVU, a presencia de disfunciones vesicales más RVU y en pacientes sometidos a estudios de pesquisa, por ejemplo por hidronefrosis antenatal, a los que se les halló RVU. Serán utilizados cefalexina, nitrofurantoína y trimetoprima-sulfametoxazol en dosis única nocturna según la edad. Se detallan sus dosis, efectos adversos, la duración de la quimioprofilaxis y otras acciones recomendadas para evitar nuevos episodios de IU. 


\section{Tratamiento de la infección urinaria}

El objetivo del tratamiento será controlar la infección aguda, evitar las complicaciones y prevenir el daño renal. Para ello será instaurado en forma precoz en un paciente con cuadro clínico compatible, sedimento urinario con signos de respuesta inflamatoria y una vez tomada la muestra para el urocultivo. Aproximadamente el $15 \%$ de los niños que hayan padecido un primer episodio de infección urinaria, desarrollarán entre 5 y 24 meses más tarde, una escara renal. Aquellos con RVU serán los que se encuentran en mayor riesgo de desarrollar una pielonefritis aguda y una cicatriz renal permanente. En ensayos clínicos y experimentales, el retraso en la instauración del tratamiento apropiado por $48 \mathrm{~h}$ en caso de pielonefritis produce un $50 \%$ más de riesgo de cicatrices.

Se indicará en el texto a qué pacientes deberá hospitalizarse y recibir antibiótico por vía EV (además de los neonatos), cuáles son los que deben elegirse según la edad, la duración según la localización de la IU y las situaciones especiales en las que debe indicarse tratamiento.

\section{Cambios respecto a recomendaciones 2008}

Se ven resumidos no sólo los cambios en el algoritmo de los estudios por imágenes sino que se reducen las indicaciones de urocultivos para diagnóstico y de "control" en los pacientes con buena evolución y/o asintomáticos.

\section{Impacto del nuevo esquema}

Describe la disminución de exámenes complementarios bacteriológicos y de imágenes que disminuyen la invasividad y la irradiación, preservando la calidad de vida de los niños con IU.

Es muy importante entender que estas recomendaciones son generales, que pueden ser modificadas en un caso en particular por el profesional idóneo que valore al niño y posiblemente estarán sujetas a nuevas modificaciones a la luz de un mayor entendimiento del desarrollo del daño renal que pretendemos evitar o minimizar, y del desarrollo y accesibilidad a mejores opciones profesionales y materiales para el diagnóstico por imágenes en todos los puntos del país.

“En verdad nadie me había preparado adecuadamente

para las maravillas de curar: la profundidad emocional, esas vivencias que ponen a prueba nuestra fe, sacudiéndola

hasta sus cimientos; el ser testigos de milagros, y el crecimiento personal más allá de lo que podamos imaginar. Analizándolo finalmente, curar nos acerca a lo más humano que existe en nosotros". 